\title{
ANARQUISMO Y EVOLUCIONISMO: RICARDO MELLA, LA COACCIÓN DEL GRUPO SOCIAL Y LA CREACIÓN «SOCIOBIOLÓGICA» DEL HOMBRE NUEVO
}

\author{
Alvaro Girón Sierra
}

Uno de los problemas básicos que tuvieron que abordar los teóricos del anarquismo internacional es el de cómo habría de organizarse una sociedad futura sin Estado y sin sistema legal, y que a su vez hiciese posible el máximo de libertad posible ¿Cómo podría garantizar una sociedad tal que no se produjeran conductas dañinas tanto para los individuos como para su conjunto? La sustitución del gobierno y la ley, por el poder "real» de la comunidad de "censurar» la conducta de los individuos se constituyó en una de las soluciones más frecuentes (1).

Ciertamente, la "censura» - que puede ir desde el intento de convencimiento por argumentos razonados a la reprobación (2) - constituye un elemento claramente coactivo que limita la libertad de los individuos (3). La estrategia de la mayoría de los teóricos se basaba, bien en negar rotundamente que la influencia social de la opinión coartase en ninguna forma la libertad individual (4), bien en tratar de demostrar que, aunque la censura pública suponga un límite a la libertad, lo hace menos que cualquier otra alternativa que tome como base el sistema legal (5). En ambos casos, la «internalización» de la «buena conducta» 
juega un papel de primer orden (6). Esta implica, como vemos, desde el primer momento, un moldeamiento de la naturaleza humana por el medio social.

En este trabajo nos vamos a acercar a cómo afrontó esta gran cuestión Ricardo Mella (1861-1925), sin duda alguna el teórico anarquista español más brillante de su época (7). Ya en el importante Segundo Certamen Socialista (1889) dibujó en su trabajo «La nueva utopía» un cuadro de lo que debía ser la sociedad futura, aunque sin entrar de lleno en la cuestión de cómo se iba a organizar una sociedad sin gobierno ni leyes (8). Aborda este problema central de manera clara en su folleto de 1901 La coacción moral (9). En él se afirma que «en una sociedad libre, basada en la igualdad de condiciones, bastará la coacción moral para mantener la armonía y la paz entre los hombres» (10). Como vemos Mella no tiene reparos en utilizar la palabra coacción. Pero también en el anarquista gallego la «internalización» ocupa un lugar primordial a la hora de hacer compatibles la paz social con el máximo posible de libertad. La idea de Mella es la de un proceso evolutivo en el que «la coacción social, identificándose poco a poco con la conciencia del individuo y con la Naturaleza, se torna a la postre en coacción moral interna, de tal manera que el hombre llega a guiarse únicamente por sus juicios, sobreponiéndose a todo motivo de temor y al temor mismo (11)». Lo que nos interesa aquí de la aproximación de Mella a este proceso evolutivo de «internalización» de la buena conducta, es la influencia decisiva que ejercen Spencer (12), y, de manera bastante más secundaria, Darwin (13), a la hora de justificarlo "científicamente» desde un punto de vista netamente evolucionista.

Antes de entrar en la parte central de la cuestión conviene que nos detengamos un momento en lo que entiende el autor por "coacción moral». Para Mella no es otra cosa que «lo que suele llamarse espíritu público porque resume las costumbres, sentimientos o ideas aceptadas universalmente en un momento dado...» (14). Ese espíritu público no obra bajo mecanismos indirectos, ni supone la imposición necesaria del mayor número sobre las voluntades individuales: «...se reduce al simple cambio no reglamentado, de influencias personales y colectivas entre todos los elementos que componen la sociedad" (15). Este intercambio de influencias, que, como vemos, no está confinado y se ejerce por todos, es recíproco, y acaba por modificar los sentimientos individuales y colectivos. Aunque indiscutiblemente supone una "presión», la coacción moral descansa, en última instancia, en el acatamiento voluntario (16). 
Se introduce, finalmente, una cuestión terminológica. Admite que en realidad está hablando de una "coacción social», pero como se la suele identificar con la «hegemonía de un todo orgánico sobre sus partes», prefiere hablar de "coacción moral» o "libre cambio de influencias recíprocas» (17). Como vemos, Ricardo Mella rechaza la idea de la sociedad-organismo (18), lo cual, parece constituir una significativa discrepancia con Spencer (19).

Sin embargo, el apoyo "científico» del filósofo inglés se hace imprescindible a la hora de articular su particular concepto evolutivo de «internalización», y sobre todo, cuando se intenta dulcificar la componente represiva que implica toda autocoacción. Según esta concepción, en una primer fase histórica, «según lo demuestra Spencer», los hombres «se guían principalmente por el temor al jefe, a la divinidad, al poder del Estado o de la ley, y finalmente de la opinión pública» (20). En la segunda fase, se produce la «internalización» -la identificación consciente o inconsciente con las influencias ambientales-. El hombre, finalmente, actúa de manera autó-noma, es decir, se obliga a si mismo independientemente de cualquier elemento de temor u otro motivo derivado de la presión externa, sin otra guía que el elemento del deber. Aquí, es donde la cita a Darwin se hace pertinente:

"Según Darwin, "los sentimientos de amistad y simpatía, lo propio que la facultad de ejercer imperio sobre si mismo, se fortalecen a pesar de todo por el hábito y como la fuerza de raciocinio progresa en lucidez y permite al hombre aquilatar la justicia de la opinión de los demás, llegará un día en que se verá obligado a seguir ciertas líneas de conducta, prescindiendo de la pena o el placer que sienta al hacerlo". "Entonces agrega- podrá decir: Yo soy el juez supremo de mi propia conducta, y repetir las palabras de Kant: No quiero violar en mi persona la dignidad humana"»(21).

Para aclarar el sentido de la cita del naturalista inglés tenemos que remitirnos obligatoriamente a su contexto. Esto es, a la explicación que desarrolla Darwin sobre el origen del sentido moral o "conciencia» en el capítulo IV de El origen del.hombre (22). Según ella, la moral reposa sobre los instintos sociales que son "seleccionados» a lo largo de la evolución. Ellos están ligados de una manera general a la «simpatía», es decir, a la capacidad de experimentar de alguna forma en carne propia los sufri- 
mientos y alegrías ajenas y que nos hace salir de nuestro ego (23). Dicha capacidad está al principio poco desarrollada, con una extensión limitada (la tribu por ejemplo) e incluye comportamientos que nosotros juzgaríamos inmorales. Con el desarrollo evolutivo de las facultades intelectuales, el efecto de la acción de la opinión de los demás y del hábito, y, en general, de la cultura, se extiende el radio de acción de la «simpatía» que se abre a un horizonte cada vez más universal.

Sin embargo, esto, por si solo, no da cuenta de la apariencia de trascendencia de la razón práctica: el origen del sentido del deber, su carácter por definición prescriptivo, parecen escapar a toda explicación «natural». No es casual, en este sentido, que el capítulo IV del Origen del hombre comience por la siguiente cita de Kant:

\footnotetext{
"iDeber! Maravilloso pensamiento que no obras por insinuación, por lisonja ni por ninguna suerte de amenaza, mas tan sólo manifestándote al alma en su desnuda austeridad, imponiendo el respeto, cuando no siempre la obediencia; ante tu vista enmudecen los apetitos todos, por tenaces que sean; en secreto, dime, ¿donde, donde tienes tu origen? (24)".
}

El desafío de Darwin es, precisamente, el de dar una respuesta a esta pregunta a través de una explicación inmanente, y al contrario que Kant, sin tener que acudir a ningún recurso más allá de lo empírico-fenoménico (25).

Desde este nuevo punto de vista, el sentido del deber no es más que la conciencia de un instinto social fuerte y persistente - "sancionado» positivamente por selección natural-, que en ocasiones se ve vencido por otros deseos o impulsos menos duraderos - por ejemplo, el hambre-, pero más poderosos en el momento en que se determina la acción. Es aquí donde el considerable desarrollo de la memoria y la reflexión en el ser humano ocupa un papel central. La memoria y la reflexión le permiten comparar, aquilatar y juzgar las acciones pasadas, presentes, y futuras; se constituyen en conditio sine qua non del ente moral (26). Por su parte, el instinto social o "simpático», al ser de naturaleza más duradera que otros impulsos o instintos, funciona, a la hora de fundamentar un juicio sobre los propios actos, como guía de conducta, como criterio permanente que permite distinguir lo bueno de lo malo (27). Se trata, en definitiva, de una "Voz interior» en toda análoga al sentimiento del deber (28).

Así pues, la ley moral no es entonces otra cosa sino una regla instintiva que ignora su propio origen. Una «sensación», un sentimiento «comple- 
jo", en cuya génesis la cultura juega cierto papel, pero plenamente explicable desde un plano empírico (29). Sin embargo, hablar de "regla instintiva» no nos debe llevar a la idea de un hombre como "autómata moral», es decir, a la anulación por definición de la moral. Por el contrario, la imagen del hombre se vuelve conflictiva. En él luchan impulsos e instintos contrapuestos. El instinto social empuja vagamente al hombre a socorrer a los semejantes, pero no en el caso de éste no toma la forma de un «instinto especial» que determine ni que lo vaya a hacer, ni la manera en que en ese posible socorro se lleva a cabo (30). Además, el desarrollo de la "simpatía» hace que cada vez aprecie en mayor grado la opinión de sus semejantes, lo cual genera nuevos móviles que pueden empujar sus actos en un sentido u otro (31).

Es a partir de aquí donde podemos determinar con más claridad el sentido del texto de Darwin citado por Mella. Como vemos, todos los desarrollos anteriores implican una ampliación progresiva del radio de elección del ser humano. Si a esto añadimos la creciente capacidad de "ejercer imperio sobre si mismo», la conclusión es que Darwin no solo intenta fundamentar empíricamente el origen del sentimiento del deber, sino lo que Kant llamaba «único principio de todas las leyes morales y los principios que les convienen" (32): la autonomía de la voluntad, la plena capacidad de determinar la propia conducta en un sentido determinado "prescindiendo de la pena o el placer que sienta al hacerlo". La autonomía, en su trascendencia, aparece, de manera paradójica, como un hecho de evolución, o dicho de otra forma, de heteronomía (33).

Ciertamente la afirmación de la autonomía y de la libertad como valores superiores, es algo a lo que siempre han estado dispuestos los teóricos anarquistas, y Mella no iba a ser una excepción. Pero, aunque para apoyar esta afirmación se acuda a Darwin, esto no significa que se siga su línea de argumentación (34), ni que el anarquista gallego sea plenamente consecuente. Si en el naturalista británico, la evolución biológico-cultural produce las condiciones de la libertad moral, en Ricardo Mella, produce la armonía entre sociedad e individuo, pero al precio de reducir al mínimo la autonomía real del último. Esta cuestión es la que vamos a desarrollar a continuación.

Como hemos visto, en el proceso de internalización — «identificación consciente o inconsciente con las influencias ambientales»- se llega a un punto en que el individuo actúa de "acuerdo consigo mismo", es decir, sin que la conducta este determinada por ningún tipo de coacción externa: se llega a la autocoacción. Sin embargo, este estadio todavía, desde el 
punto de vista de un intento teórico que busque la eliminación de todo elemento coactivo en la relación grupo social-individuo, es bastante imperfecto, ya que el sentido del deber no es sino el "eco» interiorizado de la compulsión ejercida por el grupo social tanto en el presente como en el pasado. Es entonces cuando el elemento clave de la utopía moral spenceriana entra en juego en el esquema de Mella:

«...Spencer llega (...) a la conclusión "de que el sentimiento del deber o la obligación moral es transitorio y debe disminuir a medida que la moralidad aumente"»(35).

¿Como justifica Spencer - y con él Mella - esta afirmación? Mediante dos proposiciones coordinadas. En primer lugar, mediante la idea, de que el cambio de condiciones (tanto el medio físico como el social) produce cambios concomitantes en las unidades sociales (naturalezas de los individuos). Lo importante aquí es que los sentimientos de los individuos también son susceptibles de modificaciones correlacionadas con la evolución. Según Spencer el sentido del deber no es más que un sentimiento complejo (36), y, por tanto, susceptible de cambio o incluso de desaparición.

En segundo lugar, existe una relación entre «estados de conciencia agradables y actividades útiles a la conservación de la vida" y "sentimientos desagradables o habitualmente evitados» y "actividades directa o indirectamente destructoras de la vida" (37). Como consecuencia, los placeres y dolores son relativos a las transformaciones orgánicas y morales del ser humano. Esto es de tal manera que, la naturaleza humana al transformarse hace agradables, al acomodarse a las exigencias de la vida social, las acciones necesarias a dichas exigencias y desagradables las opuestas a éstas (38). Mella resume sucintamente la forma en que se coordinan estos dos mecanismos:

«Esta bien probado que el cambio sucesivo de las condiciones modifica las costumbres, las ideas y los sentimientos de tal modo que, a medida que desaparecen las condiciones que hacían desagradables ciertos actos, se desenvuelven otros que los tornan agradables, y recíprocamente» (39). 
Finalmente a medida que se desarrolle la verdadera moral, que tiene por «sujeto propio la forma que adquiere la conducta universal en las últimas etapas de la evolución" (40), la idea y el sentimiento de obligación irán desapareciendo. La verdadera conducta moral será la apropiada al estadio social perfecto. En él se producirá un ajuste total entre las naturalezas de los individuos y los requerimientos de la vida social, entre el bien de los individuos y el bien social.' En él, el elemento coactivo presente en la idea de obligación se desvanecerá, ya que no será necesario como determinante de la conducta apropiada a las necesidades de la vida social, al estar plenamente adaptados los placeres y dolores a dichos requerimientos (41):

"Así "las cosas hoy ejecutadas con disgusto - Spencer- y sólo mediante la idea del deber, se ejecutarán con placer inmediato, y aquellas que hoy nos abstenemos por deber, serán abandonadas porque repugnarán". Conforme a esta teoría, bórrase al fin todo elemento coercitivo, toda la idea de obligación, y los actos se ejecutan "sin tener conciencia de hallarse obligado a su cumplimiento". De este modo, es evidente que el grado de dolor que supone la noción de deber es sustituido por cierto grado de placer que contiene implícitamente la ejecución espontánea de los actos, sin subordinarse a ningún motivo coercitivo» (42).

Mella matiza que «la idealidad moral, como toda idealidad, es irrealizable en sus caracteres absolutos» (43). Parece que limita, en principio el alcance de la evolución moral. El uso de la palabra "autocoacción», parece implicar que en la sociedad futura, el sentimiento de obligación no desaparecerá completamente:

«Y “como es necesario — según las mismas palabras de Spencer- que exista cierta armonía entre la conducta de cada uno de los miembros de la sociedad y la conducta de los otros" podemos establecer, sin abandonarnos a las lisonjas y las bellezas de la teoría, que en la identificación moral externa (coacción social) y la coacción moral interna (autocoacción), se resuelve el problema de la acción libre de los individuos, sin mezcla ni intervención de elementos coercitivos» (44). 
¿Es cierto que se «resuelve el problema de la acción libre de los individuos»? Desde el punto de vista de una concepción de la libertad negativa, la respuesta puede parecer afirmativa. La evolución social «libera» al individuo de todas las formas de coerción externa. Los obstáculos a la libre voluntad de los individuos desaparecen. Pero, esto se hace al precio de reducir su capacidad de elección, su auto-nomía, al mínimo. En primer lugar, aunque Mella no se pronuncie explícitamente al respecto, la visión spenceriana de la evolución moral en la que se apoya, tiene como presupuesto biológico que la naturaleza del individuo se vea determinada por la acción combinada del medio y la herencia de los caracteres adquiridos (45). En segundo lugar, el modelo de «internalización» escogido implica no sólo la aparición de disposiciones nuevas adaptadas al nuevo estado social, sino también la desaparición de los impulsos y deseos que no se conforman a la armonía prescrita entre individuo y comunidad (46). En el proceso aparece un nuevo tipo de individuo incapaz de ser «inmoral» -es decir, de generar conductas asociales-, con lo que la condición misma de la moral —la posibilidad de la inmoralidad-, desaparece (47).

Por otro lado Ricardo Mella, al igual que Herbert Spencer, se expuso a las ambigüedades que generaba la aplicación de la herencia de los caracteres adquiridos al análisis de las relaciones humanas. La velocidad y carácter del cambio social variaban de manera drástica si se subrayaba la maleabilidad del ser humano ante la acción ambiental, o si se destacaba la acción persistente del pasado a través de la herencia fisiológica. En este aspecto, el anarquista español y el positivista inglés diferirán radicalmente.

En un primer momento, el radicalismo optimista de Spencer ejemplificado por su obra Social Statics (1851), estaba fundamentado en una teoría de la maleabilidad humana. Con el tiempo, este optimismo cederá, haciéndose especialmente visible en los años ochenta en su libro The Man Versus the State (1884). El potencial pesimista del mecanismo lamarckiano se desarrolla entonces plenamente. El hombre heredaría ciertas características que no sólo llegarían a desafiar la modificación por medios políticos, sino que podrían moldear la misma sociedad (48). Esta última idea se deriva de la concepción que tiene Spencer de la interacción entre los individuos y el agregado social. Según esta, la sociedad tiende a conformar los sentimientos, ideas y necesidades de los primeros. A su vez, las modificadas «naturalezas» de los individuos hacen que la sociedad cambie en congruencia con ellas mismas (49). El Herbert Spencer pesimista de las últimas décadas del XIX pondrá el énfasis en la 
influencia del carácter de los individuos sobre las instituciones (50), y la inutilidad de todo cambio político que no lo tenga en cuenta. El nuevo caballo de batalla será el socialismo. Así se refleja en un fragmento del Individuo contra el Estado, citado - y criticado- en la revista libertaria Acracia (1886):

"Los socialistas (...), se imaginan que los defectos humanos pueden ser corregidos a fuerza de habilidad por buenas instituciones. Es una ilusión. Cualquiera que sea la estructura social, la naturaleza defectuosa de los ciudadanos ha de manifestarse necesariamente en actos perniciosos. No hay alquimia política bastante poderosa para transformar instintos de plomo en conducta de oro" (51).

El recurso a la herencia fisiológica, por su parte, le sirve a Mella para justificar la perversión "actual» del espíritu público, del instrumento privilegiado a través del cual se ejerce la coacción moral (52). Según Ricardo Mella, la observable persistencia de falsos prejuicios sobre moral y honor, que informan en multitud de ocasiones la conducta del pueblo, se explica por la acción de una herencia fisiológica que tiende a perpetuar costumbres ya obsoletas. Sin embargo, también es patente, según el anarquista gallego, la tendencia a emanciparse de los «errores tradicionales». Pero el Estado, enemigo del progreso, fomenta los efectos perversos de la transmisión hereditaria (53). De esta manera, se transfiere el peso del «mal» a lo externo, a las instituciones coercitivas, a la vez que se diluye la potencialidad regresiva de la herencia en los individuos.

Como consecuencia, para "sanear» el espíritu público hay que empezar por la eliminación de todos los poderes coactivos. Con la desaparición de éstos, se producirán "nuevos efectos derivados de causas nuevas», es decir. "de una vida armónica, fraternal, solidaria en los intereses, resultaría necesariamente el amor, la amistad, la abnegación» (54). Vemos, pues, que un cambio en las condiciones sociales (ambientales) resulta en un cambio positivo en las disposiciones de los individuos (naturalezas). A su vez -y en esto se sigue también la lógica spenceriana- si «en una sociedad libre los hombres se modificarían» es coherente pensar que «la coacción moral (...) se modificaría también ennobleciéndose...» (55). Dicho de otra forma, una vez iniciada la adecuada intervención ambiental se establece una interacción positiva entre individuo y círculo social inmediato, que progresivamente irá mejorando a ambos. 
Queda claro, pues, que hay que empezar por la modificación de unas condiciones que «invierten» el sentido de la coacción moral. En esto se separa explícitamente de Spencer. La Revolución pasa a ser la llave maestra, la necesaria y perentoria alteración de aquellas condiciones. No cabe esperar a la modificación previa de la naturaleza de las unidades sociales:

«¿Pero es posible realmente empezar por la modificación de las costumbres para obtener la modificación de las condiciones? (...) El proceso de adaptación se opera bajo el punto de vista ideal, no real. El progreso es una serie de adaptaciones en el dominio del pensamiento, no en el de los hechos. Por eso, no obstante todas las pruebas aducidas por Spencer, quiebran en la práctica ciertas afirmaciones del positivismo (...) si en general, ciertas modificaciones de las costumbres permiten afirmar el embrión de un camino más o menos próximo, favorable a un estado social mejor, como hemos indicado repetidamente, nada nos lleva a la rotunda afirmación de que "nuevos progresos de la simpatía, desenvolviendo aquella manera de ser, le darán carácter general. (...) Cierto que las costumbres pueden progresar (...), pero sin que de ningún modo salven la barrera del egoísmo, sostenido por la propiedad privada y por el privilegio del poder. Es un progreso potencial que se desenvolverá de golpe por la supresión o el arrollamiento de todas las barreras. (...) Es, pues, necesario empezar por la modificación de las condiciones...» (56).

\section{NOTAS}

(1) Los estudios sobre las diversas teorías anarquistas han advertido como éstas conceden al papel de la «censura" un lugar central en la sociedad futura. Uno de estos trabajos, el de Alan Ritter, ofrece un breve pero significativo resumen de lo que afirmaban al respecto algunas de las figuras más conocidas en la historia del pensamiento libertario: «En la anarquía de Godwin "el examen de cada hombre sobre la conducta de sus vecinos... constituiría una censura de la naturaleza más irresistible", a la que "ningún individuo sería lo suficientemente temerario de desafiar". Proudhon confía en la censura en el estado de anarquía de tal manera que "actúe sobre la voluntad como una fuerza y la haga elegir el buen camino". Bakunin sigue a Proudhon al ver "el espíritu colectivo y público" de una sociedad anarquista como "la única gran y todopoderosa autoridad...que podemos respetar". Y Kropotkin es perfectamente cándido al explicar lo que hacer "cuando vemos un acto antisocial cometido" en estado de anarquía. Nosotros debemos "tener el coraje de decir alto en presencia de todo el mundo lo que pensamos de tales actos"». RitTER, A (1980), Anarchism. A theoretical analysis, Cambridge, p. 9. ' 
(2) La censura, de hecho, no excluye en ocasiones elementos claramente represivos. Jean Grave, figura central en la historia del anarquismo en Francia, da buen ejemplo de ello: «Apretando la solidaridad todos los lazos sociales y no formándose estos sino en virtud de las afinidades, todo individuo que tratase de causar perjuicio a un miembro de la sociedad se vería inmediatamente reprobado por el medio en el cual viviese, pues cada persona comprendería que si dejaba cometerse un acto de injusticia sin descubrirlo, sería dejar la puerta abierta para otros que más tarde pudieran cometerse contra él. El agresor expulsado de todas partes, al rehuir todas sus relaciones el trato con él, comprendiendo que la vida la sería imposible, corregiríase mejor que aprisionándole...». GRAVE, J. (s.f), La sociedad futura, Valencia, Tomo II, pp. 192-193.

(3) Ritter señala que él descrédito del anarquismo en la teoría política se debe a la supuesta contradicción existente entre postular, por un lado, la libertad ilimitada, y recurrir, por el otro, a la censura pública para controlar el comportamiento. La tesis que sostiene el mismo autor es que la libertad no es el principal valor político - y por tanto absoluto- entre los anarquistas, sino que su objetivo era el de buscar una sociedad que combine la mayor libertad individual con la mayor unidad dentro de la comunidad [RITTER (1980), pp. 2-3]. Sin embargo, a nuestro juicio, la libertad no siempre aparecía como un valor subordinado. Las afirmación de la libertad absoluta no era rara, no sólo entre los individualistas stirnerianos, que al fin al cabo constituyeron una corriente minoritaria y marginal dentro del anarquismo mundial, sino, por ejemplo, en el propio Bakunin. $\mathrm{El}$ anarquista ruso llegó a "admitir que el individuo se adhiera a grupos cuyos fines sean corromper y destruir la libertad individual o pública», antes de aceptar el limitar el derecho a una libertad absoluta y completa. Guérin, D. (1968), El anarquismo, Buenos Aires, p. 42.

(4) Intentando hacer ver, por ejemplo, que la censura de la opinión pública es tan inevitable como lo es una ley natural, y, por tanto, los límites que impone a la libertad son de la misma clase que los que impondría algo que no puede ser evitado (un caso claro es la muerte). En el caso de Bakunin, la influencia de la opinión pública cae bajo la esfera de las leyes sociales. Sobre éstas afirma: «El hombre nunca podrá ser libre respecto de las leyes naturales y sociales. Estas leyes, que por conveniencia de la ciencia se dividen en dos categorías, pertenecen en realidad a una sola, porque son todas leyes igualmente naturales...». De esta forma "la influencia natural que ejercen unos hombres sobre los otros, es también una de esas condiciones que no puede subvertirse». BAKUNIN, M. (1978), Escritos de filosofía política, Madrid, p. 202.

(5) Según Ritter el gobierno legal es «un método de control señalado por las siguientes características: es aplicado por un pequeño número de agentes, quienes establecen reglas generales y permanentes para todos los miembros de la sociedad y que hacen cumplir estas reglas mediante penas fijadas para cada tipo de delito". La censura, según los anarquistas es comparativamente mejor porque: a) al ser el número de agentes del gobierno poco numeroso, la información que tienen de los individuos es escasa, con lo que son tratados como un grupo indiferenciado, mientras que la "censura» al descansar en cada uno de los individuos de la comunidad, permite ajustar las directivas y sanciones a las circunstancias de cada uno; b) la ley exige - dada su generalidad - a toda una clase de individuos comportarse de la misma manera en una variedad grande de circunstancias, mientras que la censura opera mediante imperativos singulares que se prescriben, no de acuerdo a máximas previamente escritas, sino en función de cada caso particular; c) las 
leyes no se ajustan tan rápidamente — dada su permanencia - a las circunstancias cambiantes. RITTER (1980), p. 19.

(6) Irving L. Horowitz dice al respecto que «la anarquía como afirmación; significa (...), la internalización de las normas de conducta en grado tan elevado que elimina por completo la necesidad de la coacción externa». HoRowitz, I.L. (1982), Los anarquistas. 1. La teoría, Madrid, p. 14. Se trata de operar la conversión de lo externo-coactivo en inmanente-no represivo.

(7) La figura de Ricardo Mella como teórico ha llamado la atención de los historiadores del movimiento obrero. Hobsbawm afirma que a excepción de él «no hay teórico anarquista ibérico importante». HoвSBAwм; E.J.(1983), Rebeldes primitivos, Barcelona, p. 130. Sobre Mella, se pueden consultar entro otros, MuÑoz, W. (1974), Antología ácrata española, Barcelona; SEgARRA, A. (1977), Federico Urales y Ricardo Mella, teóricos del anarquismo español, Barcelona; FERnÁndez Alvarez, A. (1990), Ricardo Mella o el anarquismo humanista, Barcelona; Lово, J.A. (1979), "El anarquismo humanista de Ricardo Mella», Estudios filosóficos, 77, vol. XXVIII.

(8) «La nueva utopía» ha sido reeditada recientemente en GómEz TovAR, L. y PANIAGUA, J. ed. (1991), II. Utopías libertarias españolas, Madrid. En este mismo libro (pp. 25 34) Gómez Tovar analiza el trabajo de Mella. Véase también al respecto, SEgarRa (1977), pp. 71 y 72 .

(9) Ricardo Mella dice lo siguiente sobre el proceso de elaboración del folleto: «Hace algunos años escribí este pequeño trabajo que amigos muy queridos intentaron publicar en forma de folleto. A pesar de sus buenos deseos, no podrá ver la luz sino en periódicos de Norte América y Cuba, y aún esto de manera incompleta. Puede, pues, decirse que son estas páginas casi desconocidas en España. Y respondiendo a excitaciones de otros amigos no menos queridos, he revisado y corregido las antiguas cuartillas». MELLA, R. (1901), La coacción moral, Madrid, p. 5. Sobre lo afirmado por Mella, tenemos conocimiento de que aparecieron partes de La coacción moral, Madrid, en El Despertar de Nueva York en 1893. Lo interesante de este hecho, desde el punto de vista de la trayectoria intelectual del autor, es que parece que las ideas fundamentales sobre las que descansa el texto parece que han madurado años antes de 1901. Esto explicaría la discrepancia existente entre esta obra - que se apoya de manera muy importante en la ética spenceriana-y el folleto aparecido en 1900, Del amor. Modo de acción y finalidad social, donde se revisan de manera muy crítica parte de los fundamentos sobre los que descansaba el evolucionismo de Spencer.

(10) Mella (1901), p. 7.

(11) Mella (1901), p. 9.

(12) La influencia de Herbert Spencer en Mella es grande. Es algo que el mismo reconoce, (véase Mella, R. (1926), Ideario, Tomo I de las Obras Completas, Gijón, p. 5) y que la bibliografía más reciente ha señalado [FERNÁNDEZ ALVAREZ (1990), p. 92.; LoBo (1979), p. 76]. En el caso concreto de La coacción moral es notable la impronta de las obras de ética de Herbert Spencer. De entre ellas, sin duda, la que ejerce más influencia es The data of Ethics, publicada por primera vez en 1879. Existe una traducción española (S. García del Mazo) de 1881 aparecida en Madrid bajo el nombre Fundamentos de la moral .No se puede descartar que Mella leyera la obra directamente en inglés (de la misma manera que leía -Nettlau, M. (1969), La Première Internationale en Espagne (1868-1888), DoRdRECHT, p. 586- revistas como The Alarm, Freedom o Liberty). Nosotros hemos utilizado la traduc- 
ción francesa de 1880 al no encontrar en la Biblioteca Nacional de Madrid la edición española.

(13) Mella transcribe dos fragmentos del capítulo IV de El origen del hombre. En este capítulo se trata, fundamentalmente, de proponer una posible explicación evolutiva del origen del sentido moral. Sin embargo, veremos cómo no es la línea de argumentación de Darwin la que realmente le interesa, sino la de Spencer.

(14) Mella (1901), p. 8.

(15) Mella (1901), p. 8. Cabe preguntarse si la visión de Mella de las relaciones humanas no presenta un rasgo muy característico del anarquismo señalado - y criticado " duramente- por Horowitz: «El anarquismo ha sido tradicionalmente un fracaso, en parte debido a que nunca fue capaz de contemplar la vida practica de los hombres como algo que se extiende más allá de unas relaciones cara a cara». HoRowitz (1982), Tomo I, p. 65.

(16) Mella (1901), p. 8. En nuestra opinión el modelo trazado aquí por Mella se aproxima bastante al que describe Bakunin en el siguiente fragmento: "Cada uno es autoridad dirigente y cada uno es dirigido a su vez. Por tanto, no hay autoridad fija y constante, sino un cambio continuo de autoridad y de subordinación mutuas, pasajeras y sobre todo, voluntarias». Citado en Velasco Criado, D. (1993), Ética y Poder Político en M. Bakunin, Bilbao, p. 174. Se trataría de una sociedad en la que según el comentario de Velasco Criado, "todos son maestros y discípulos, en donde la autoridad se basa en el puro consentimiento». Velasco Criado (1993), p. 175.

(17) Mella (1901), p. 9.

(18) Mella quiere advertir, fundamentalmente, que la coacción a la que el se refiere es una coacción «real» - es decir la que se extiende en círculos concéntricos desde la familia hasta el resto de los hombres-, no una cierta "coacción nebulosa derivada de un ente metafísico y ejercida casi misteriosamente, según pretenden todos los que, hablándonos de derecho social, de sentimiento colectivo, de salud pública, etc., colocan en el pináculo de su rara teología una sociedad sui-generis, distinta de sus componentes, superiores a ellos, y más santa y más venerada que ellos mismos; una entidad todopoderosa que habla, no por las bocas de los que la constituyen, sino por medios providenciales, y piensa y siente y actúa por propios y particulares impulsos, como si tuviera cuerpo real y órganos adecuados de expresión, a semejanza de lo que hacen los creyentes con su dios antropomórfico». MELla (1901), p. 18.

(19) Según Leszek Kolakowski, Spencer observa «una analogía real y profunda entre los caracteres estructurales y funcionales de una sociedad, por una parte, y las cualidades de los organismos vivos por otra». KolAKowsKI, L. (1979), La filosofía del positivismo, Madrid, p. 119. Hay motivos políticos para apoyarse en el organicismo: «...a la recusación constante de un intervencionismo estatal que sobrepone sus normas a la espontaneidad de los individuos libres, corresponde la representación del desarrollo de un organismo por autorregulación; el orden político y el orden biológico (...) se unifican en la simbiosis de un auto-dinamismo" CONRY, Y. (1987), Darwin en perspective, París, p. 87. Sin embargo, desde el punto de vista de una filosofía ultraindividualista, la equivalencia sociedadorganismo no deja de ser problemática: Spencer abraza claramente la equivalencia entre sociedad y organismo en los Principles of Sociology (1876), mientras que The Man versus the State (1884), afirma que la sociedad no es nada en si misma, sino una limitación de mutuas actividades, un sistema de equilibrio entre las fuerzas individuales (DE Vos, p. J. (1970), Herbert Spencer as positivist-organicist: contradiction in his theories, Fort Hare 
University, p. 12.). Para Patrick Tort hay que distinguir en Spencer un primer organicismo estático (la sociedad es como un organismo) y otro dinámico posterior (la sociedad evoluciona como un organismo). El primero será abandonado por el filósofo inglés ya que podría "naturalizar» un cierto dirigismo estatista: la analogía entre sistema nervioso central y algún tipo de centro director de la sociedad es demasiado evidente. No renunciará, sin embargo al segundo (vid. ToRT, p. , "Spencer et le système des sciences», estudio preliminar a: SPENCER, H. (1987), Autobiographie. Naissance de l'evolutionisme liberal, París, pp. XLIII y XLIV). Un resumen de lo que considera el filósofo inglés como análogo en la sociedad y y el organismo individual, en SPENCER, H. (1883), El universo social, Barcelona, Tomo II, pp. 438-439.

(20) Mella (1901), p. 197. Para Spencer, los tres «controles» (político, religioso, social), aunque no generaban el «control» propiamente moral, preparaban su desarrollo. Según el positivista británico la evolución de la conciencia moral, es prácticamente idéntica a la subordinación de los sentimientos más simples a los más complejos. Los más complejos son aquellos que subordinan las satisfacciones próximas a las lejanas y viceversa. Precisamente, es con medios de coacción desarrollados cuando se pueden dar las experiencias suficientes que hagan familiares los beneficios de la subordinación de los sentimientos simples a los complejos. De hecho la aparición de los sentimientos propiamente morales - y los frenos correlativos- se da en una época tardía de la evolución humana, al no darse anteriormente las condiciones de su desarrollo. Vid. SPENCER, H. (1880), Les bases de la morale évollutioniste, París, pp. 98-99, 102 y 105.

(21) Mella (1901), pp. 9-10.

(22) Véase Darwin, Ch. (1982), El origen del hombre, Madrid, pp. 100-128. En cuanto a la interpretación de ésta parte de El origen del hombre, hemos seguido muy de cerca la de Quiniou, Y. (1992), "La morale comme fait d"évolution», en ToRT, p. (ed.), Darwinisme et societé, París, pp. 47-54.

(23) Distinta del amor, la «simpatía» descansa en la fuerza de la retentiva, que «nos hace no olvidar antiguos estados de placer o dolor. De aquí, que a la vista de "otra perșona, víctima del hambre, del frio" se excite en nosotros algún recuerdo de estos estados, y nos veamos impelidos a aliviar el sufrimiento ajeno, "con el fin de aliviar al propio tiempo el sentimiento de tristeza engendrado por el espectáculo de la desgracia" [DARWIN, Ch. (1982), p. 108]. Darwin se apoya aquí, fundamentalmente, en Adam Smith (en especial su obra de 1759 Teoría de los sentimientos morales) y en el psicólogo Alexander Bain (véase al respecto RAPHAEL, D.D. (1979), "Darwinismo y ética», en BARNETT, S.A. (ed), Un siglo después de Darwin. 1. La evolución, Madrid, 209-246; pp. 213-214.).

(24) DARWIN (1982), p. 101.

(25) Para Kant el origen «digno» del poder del deber no "puede ser menos que lo que eleve al hombre por encima de si mismo». KANT, I. (1977), Crítica de la razón práctica, Buenos Aires, p. 94.

(26) La afirmación de Darwin no puede ser más contundente: «...llamamos morales todas las acciones de cierta clase llevadas a cabo por un ente moral, el cual no es un más que un ser capaz de comparar sus acciones o motivos pasados y futuros, y aprobarlos y desaprobarlos». DARWIN (1982), p. 113.

(27) En el siglo pasado, el filósofo francés J.B Guyau resumió con acierto la posición de Darwin: «Hay más. Hay un elemento que no hemos introducido todavía en la cuestión: la memoria y la reflexión. Suponed que los instintos morales o sociales entran en lucha 
con algún deseo súbito, violento (...) como el hambre, como una pasión, como el odio: son vencidos. Pero una vez saciada el hambre o el rencor satisfecho, el placer nacido de esta satisfacción se disipa: los instintos sociales quedan persistentes y vivos: tienen por si todo el pasado, todas las tendencias, todos los hábitos acumulados lentamente por la herencia; no tienen contra si más que un momento de placer, ya desaparecido y lejano. Cuando entonces la inteligencia recogiendo con la reflexión el acto realizado, lo compara a las exigencias del instinto social, siempre vivo y presente, no puede no tomar horror a este acto; en estas condiciones el recuerdo de la derrota sufrida por el instinto social, toma necesariamente la forma de un remordimiento. Lo mismo, la previsión de una victoria conseguida por este mismo instinto tomo par necesidad la forma de un deber». GuYAU, J.M. (s.f.), La moral inglesa contemporánea. Moral de la utilidad y de la evolución, Madrid, pp. 226227.

(28) Hay que aclarar que lo que Darwin intenta explicar con el recurso a la persistencia del instinto social, es el carácter prescriptivo, "obligatorio" del sentido del deber, no de establecer un "contenido" para la ética. De hecho, el contenido de lo que se deba o no se deba hacer, lo que sea "bueno" o "malo", depende en gran medida de las circunstancias ambientales y la historia evolutiva particular de cada especie. El ejemplo que utiliza el propio Darwin es bastante explícito: «Bueno será que, ante todo, advierta que no es $\mathrm{mi}$ intento sostener que un animal rigurosamente sociable deba adquirir en todo el mismo sentido moral que nosotros, suponiendo que sus facultades morales llegaran a tanta actividad y desarrollo como el hombre (...). Así, para usar un ejemplo extremo, si se reprodujeran los hombres precisamente en las mismas condiciones que las abejas, no cabe la menor duda que las abejas trabajadoras, las hembras no casadas, tendrían por deber sagrado matar a sus hermanos, y que las madres procurarían destruir a sus hijas fecundas, sin que nadie pensase en intervenir. Sin embargo, en esta suposición, la abeja o cualquier otro animal social alcanzaría, según creemos, algún sentimiento de lo bueno o lo malo, es decir, una conciencia». DARWIN (1982), p. 102. El texto citado nos puede llevar a la conclusión de un profundo relativismo moral y a la idea de que la cita kantiana encierra un grado importante de inconsecuencia [HowARD, J. (1987), Darwin, Madrid, pp. 106-110]. En nuestra opinión, sin embargo, aunque el horizonte de universalidad se restringe dramáticamente (no existe un "bueno" o "malo» absolutos para cualquier ente racional), lo importante, y lo que hace pertinente la referencia a Kant, es que si existe una única referencia moral — «nuestro" particular instinto social— para todos los seres humanos.

(29) Quiniou (1992), p. 51.

(30) La razón y la experiencia sustituyen progresivamente la acción del instinto a la hora de establecer el modo de auxiliar al prójimo: «Aunque el hombre, como acabamos de notar, no posee instintos especiales que le enseñen cómo debe ayudar a sus prójimos, sin embargo, existe en él ese natural impulso; y con sus altas facultades intelectuales, naturalmente se deja guiar en esto por la razón y la experiencia». DARWIN (1982), p. 111.

(31) «La simpatía instintiva que posee le hace apreciar vivamente la aprobación de sus semejantes; porque como Bain ha demostrado, el amor a la alabanza, el sentimiento vehemente de la gloria y el horror aún más grande al desprecio y a la infamia "son debidos a los efectos de la simpatía". Por consiguiente, ejercen influencia muy grande en el hombre y su conducta los deseos, la apreciación o la censura de sus semejantes (...). De este modo, pues, los instintos sociales que el hombre debió adquirir cuando se hallaba en una época grosera de su vida, probablemente por sus progenitores de forma símica, dan 
todavía impulso a muchas de sus mejores acciones, pero éstas se determinan principalmente por los deseos y juicio de nuestros semejantes...». Darwin (1982), pp. 111-112. Vid. también GuYau (s.f), p. 230.

(32) Kant (1977), p. 39

(33) Como dice Yvon Quiniou, «se destruye el dispositivo ideológico fundador en Kant, es decir, el idealismo, y no la cosa en si». Quiniou (1992), p. 52. Nota 20.

(34) El aspecto dé Darwin que interesó más a Mella es el relacionado con el «automatismo de las acciones» [Mella (1901), p. 9] y el de la posible "fijación por herencia» de los hábitos morales: "Al pensar - afirma Darwin- en las generaciones futuras, no hay ningún motivo para temer que en ellas se debiliten los instintos sociales, y podemos admitir que los hábitos de virtud adquirirían mayor fuerza fijándose por la herencia». Mella (1901) p. 52. [cf. DARWIN (1982), pp. 126-127]. Como vemos, Ricardo Mella estaba más interesado en apuntalar "científicamente» la idea de la "no posibilidad" en la sociedad futura de conductas dañinas para la comunidad, que en fundamentar un concepto positivo, y no meramente negativo de la libertad.

(35) Mella (1901), p. 10. Es el mismo texto de Spencer (1880), p. 110. Vid. también SPENCER, H. (s.f), La moral de los diversos pueblos y la moral personal, Madrid, p. 48. La idea ya está presente en Mella en el Segundo Certamen Socialista: «Siguiendo estas ideas, Spencer deduce la consecuencia necesaria de la proximidad de un estado social, en el que la obligación como elemento de la conciencia colectiva desaparecerá, y en la que los individuos se guiarán únicamente por los sentimientos morales, como hoy se guían por las sensaciones». Mella (1890); «La Anarquía», en Segundo Certamen Socialista, pp. 54-72; Barcelona, p. 66.

(36) Un sentimiento que según la crítica de Spencer a Kant es una «inclinación» de naturaleza nada suprasensible y que tiene su origen en el proceso evolutivo. El sentimiento de deber tiene dos componentes fundamentales. Por una parte, la experiencia acumulada ha generado la conciencia de que la dirección a la conducta dada por los sentimientos que se conectan con resultados lejanos y generales, contribuyen ordinariamente mejor al bienestar que la dirección dada por los sentimientos que dirigen a la satisfacción inmediata. La idea de que existe un "valor» diferencial en función de la utilidad en la dirección de la conducta, constituye un elemento del sentimiento de obligación. Por la otra, la coerción exterior interiorizada (ambiental y hereditariamente) produce la incitación a la acción que encierra la conciencia de obligación [SPENCER (1880), p. 109]. Sobre la idea del sentido del deber como «inclinación" véase SPENCER, H. (1894), Problèmes de Morale et de Sociologie, París, pp. 39-40.

(37) SPENCER (1880), p. 67.

(38) Véase SPENCER (1883), Tomo I. pp. 121 a 126. En estas páginas del prólogo del libro, Salvador Sanpere i Miquel director de la Revista de Ciencias Históricas, discute las consecuencias filosóficas y éticas de la relatividad de los placeres y dolores. Sobre esto hay que decir que el papel del placer y el dolor era central en la concepción que tenía Spencer de la dirección de la conducta. La idea del psicólogo Alexander Bain en torno al fundamento de la acción voluntaria -el incremento de la frecuencia de un movimiento se produce cuando este ha ido seguido de un acontecimiento placentero-fue aceptado por Spencer que redefinió el placer como un estado de conciencia que se trata de prolongar, y el dolor como un sentimiento que se trata de sacar de la conciencia (BOAKES, R.A. (1989), Historia de la psicología animal. De Darwin al conductismo, Madrid, p. 33. pp. 36-37). Así, 
para Spencer, el mero conocimiento de algo, no mueve a la acción, sino el sentimiento asociado a este: « $\mathrm{Si}$ al andar me clavo una espina, o si por inadvertencia meto mi mano en el agua hirviendo, me estremezco: la sensación fuerte produce el movimiento sin intervención del pensamiento. Al revés, la proposición que me enseña que un alfiler pica y que el agua escalda, me deja indiferente». SPENCER (1883). Tomo I. p. 366.

(39) Mella (1901), p. 10.

(40) SPENCER (1880), p..16. A esta estadio de la evolución corresponde la verdadera conciencia moral. La conciencia moral se caracteriza por considerar las efectos «intrínsecos» de las acciones. Trata de determinar las condiciones que contribuyan por si mismas a la mayor felicidad del individuo y la sociedad, y no considera los actos en función de su conformidad con las sanciones sociales (criterio «extrínseco») SPENCER (s.f), pp. 27-28.

(41) Mella cita páginas más adelante una contundente cita de Spencer al respecto: «Los placeres y dolores (Spencer) que tienen su origen en el sentimiento moral, llegarán a ser, como los placeres y dolores físicos, causas de acción o abstención, tan bien adaptadas en fuerza a las necesidades que la conducta moral será la conducta natural». MELla (1901), p. 48 [texto prácticamente idéntico en SPENCER (1880), p. 113].Dada la velocidad en el cambio de las condiciones sociales, resulta un desajuste parcial de las sensaciones o deseos, placeres y dolores y el nuevo estadio social. Spencer constata que, "durante la evolución social, las ideas y los sentimientos apropiados a las actividades militantes desarrolladas por una cooperación impuesta son cambiadas por ideas y sentimientos apropiados a las actividades industriales..». Sin embargo, "existe todavía en el seno de cada sociedad, un conflicto entre las naturalezas morales adaptadas a estos dos géneros de vida diferentes». Por tanto es necesaria «la readaptación de la constitución a las condiciones» que «implica un nuevo ajuste de los placeres y penas como guías morales». [SPENCER (1880), p. 73.]. En el estadio social perfecto, como vemos, el ajuste se consumará.

(42) Mella (1901), p. 10. Cf. Spencer (1880), p. 158

(43) . Mella (1901), p. 10.

(44) Mella (1901), p. 11. Cf. SPEnCER (1880), p. 240. La cuestión, en cualquier caso, no queda clara. Páginas más adelante, Mella parece no renunciar al horizonte utópico de la desaparición total del sentimiento de obligación. La posibilidad de tal desaparición viene propiciada por el cambio de condiciones generado por la revolución social: «Transformar en placer el cumplimiento de los deberes llegar a esta identificación de la conducta moral y de la conducta natural, será la obra del desenvolvimiento futuro de una revolución social que produzca la verdadera libertad y la igualdad social...». Mella (1901), p. 48.

(45) La contradicción en Spencer entre afirmación de la libre voluntad y moldeamiento de la naturaleza humana por la acción combinada del medio y la herencia de los caracteres adquiridos es señalado por WiLTSHIRE, D. (1978), The social and political thought of Herbert Spencer, Oxford, p. 237. La aplicación de la herencia de los caracteres adquiridos a este dominio, hace que no puede existir auténtica «autodeterminación». Guyau, al comentar la obra de Spencer lo se da cuenta de ello: «....no soy yo mismo quien me obligo (...) mi obligación y mi voluntad no tienen ese poder por si solas; la necesidad moral no es sino la manifestación de una potencia, que me es anterior y superior: la potencia del pasado». GuYau (s.f.), p. 470. Ricardo Mella, por su parte, defiende pocas páginas después un determinismo matizado en el tema de la libertad del individuo. Existen tanto el "fatalismo ambiente» como el "fatalismo orgánico», pero existe una tendencia hacia la emancipación. Esta tendencia es signo de la existencia de un «elemento más» (razón, con- 
ciencia), evidenciado al existir deliberación, lucha, a la hora de tratar de impulsar la acción en un sentido u otro. Sin embargo, apenas «se puede decir que somos capaces de refrenar nuestros impulsos». MELla (1901), pp. 43-44.

(46) WiltshiRe (1978), p. 239.

(47) Como vemos, en el planteamiento de Mella y Spencer la identidad "final» entre moralidad y conducta apropiada desde el punto de vista social es total. Filósofos franceses de la época, como Guyau, criticaban la identificación excesiva de moralidad e «instinto social" [sobre en los filósofos ingleses (Spencer y Darwin)]. Para el francés, existen esfuerzos que podrían caracterizarse de «morales» que se ejecutan independientemente de los instintos sociales de la raza. Guyau elaboró una fundamentación alternativa para la ética de enorme influencia, especialmente intensa en determinados sectores libertarios. Frente a la idea de una evolución biológica y social que determina la aparición -más o menos tardía y adventicia- de los instintos sociales y "morales», Guyau prefiere hablar de una "fecundidad moral" derivada de la tendencia de la vida misma a expandirse, y por tanto, a comunicarse. Los placeres y dolores no son ya los resortes conscientes o inconscientes de la conducta: la vida se desarrolla y se ejerce "porque es la vida" con independencia de aquellos. El principio de la vida "expansiva», le permite, finalmente, dar cuenta del origen del sentimiento de obligación. La conciencia de la obligación es la conciencia del "poder": sentir interiormente lo que uno es capaz de hacer es el deber hacer (FouILLÉE, A. (1902), La moral, el arte y la religión según Guyau, Madrid pp. 118, 120-1 y 147; GUYAU (s.f), pp. 597-598). Es importante destacar que esta concepción de Guyau tuvo bastante influencia en La moral anarquista, obra de Pedro Kropotkin, uno de los más influyentes libertarios europeos. Para el anarquista ruso, el filósofo francés había encontrado el "verdadero camino", allá "donde las filosofías kantianas, positivista y evolucionista se habían estrellado». KROPOTKIN, p. (1977), La moral anarquista, Madrid, p. 45. También Woodcock, G. y Avakumovic, I. (1975), El Príncipe Anarquista, Madrid, pp. 16-17.

(48) Vid. WiltSHIRE (1978), p. 210. Sobre el contraste entre el optimismo liberal del Spencer de los años cincuenta, congruente con una economía en expansión, y el pesimismo de los ochenta, derivado en parte, por la creciente intervención del Estado británico en los años 1870-1884, vid. BECQUEMONT, D. (1992), «Aspects du darwinisme social anglosaxon» en TORT (ed.), 137-167; pp. 142 a 146 y 152 a 155.

(49) «Tan pronto como una combinación social adquiere alguna permanencia, principian las acciones y reacciones entre la sociedad considerada en su masa y cada uno de sus miembros en particular, de modo que cada miembro afecta la naturaleza del otro. La influencia del agregado sobre sus unidades, tiende sin cesar a conformar sus maneras de obrar, sus sentimientos y sus ideas a las necesidades sociales; y estas actividades, sentimientos e ideas, en tanto cuanto están modificadas por el cambio de las circunstancias, tienden a remoldear de nuevo la sociedad en congruencia con ellas mismas». SPENCER (1883), Tomo II, p. 19.

(50) WILLTSHIRE (1978), pp. 211-212. Los comentadores de la sociología spenceriana han señalado la clara inconsecuencia de este viraje: «Spencer olvida su propia afirmación de que hay una relación recíproca entre la organización social y la naturaleza humana y de que la naturaleza humana, cualquiera que sea, es susceptible de cambios». RUMNEY, J. (1944), Spencer, México, p. 171.

(51) L. (1886), "El individuo contra el Estado. Spencer y La Revue Socialiste», Acracia, 5, 34-36; p. 35. El mismo texto en SPENCER, H. (s.f), El individuo contra el Estado, Va- 
lencia, p. 91. Según el gran patriarca del anarquismo hispano, Anselmo Lorenzo (personaje que se escondía bajo "L»), el filósofo inglés "...ha examinado los hechos, ha confundido los que pueden considerarse como resultado fatal del proceso evolutivo con los producidos por los errores de los sistemas» L. (1886), p. 35.

(52) Afronta aquí la evidente ambivalencia del poder de la opinión pública, comentado ya por Bakunin: «...ese poder de la sociedad puede ser lo mismo perjudicial que provechoso. Es provechoso cuando tiende al desarrollo de la ciencia, de la prosperidad material, de la libertad, de la igualdad y de la solidaridad fraternal de los hombres; es perjudicial cuando ofrece tendencias contrarias". BAKUnIN, M. (s.f), Dios y el Estado, Barcelona. p. 24

(53) Mella (1901), pp. 28-29.

(54) Mella (1901), pp. 30-31.

(55) Mella (1901), p. 51.

(56) Mella (1901), pp. 54-55. Ya en 1889, en La Solidaridad, periódico redactado por Mella, se decía los siguiente: «Es pues, necesario cambiar las condiciones de viabilidad de la evolución, modificar el medio ambiente, para que aquella se desenvuelva fuera de toda clase de obstáculos que no sean los naturales. ¿Y como modificar estas condiciones? Por la revolución y sólo por la revolución...». REDACCION, (1889)a., "Evolución y Revolución», La Solidaridad, 23, 1; p. 1. En el Segundo Certamen Socialista Mella se pronunciaba en términos muy parecidos: «Soñar con que la evolución se complete en un medio que le es totalmente opuesto, es una locura. Para completarse aquella, lo repetimos, es indispensable modificar antes el medio circundante, provocar la revolución...». MELLA (1890), p. 69. 